\title{
Severe granulomatous peritonitis and small-bowel fistula formation following the excision of an ovarian dermoid cyst: a case report
}

\author{
A. Malhotra • C. Grimes • M. Nikolić
}

Received: 20 August 2007 / Accepted: 9 September 2007 / Published online: 16 October 2007

(C) Springer-Verlag 2007

\begin{abstract}
Dermoid cysts are the most common type of ovarian tumour and should be removed due to possible complications. We report a case of a woman who suffered severe granulomatous peritonitis following laparoscopic removal of a dermoid cyst. This required laparotomy, with subsequent enterocutaneous fistula formation. This case demonstrates the importance of adequate irrigation and the use of an endobag in removing dermoid cysts laparoscopically.
\end{abstract}

Keywords Dermoid cyst · Peritonitis · Laparoscopy · Enterocutaneous fistula $\cdot$ Endobag

\section{Introduction}

Dermoid cysts, more accurately known as benign cystic teratomas, are the most common type of ovarian tumour, comprising approximately $20-25 \%$ of all ovarian tumours [1]. They are usually discovered incidentally during pelvic ultrasound or examination. Surgical removal is advised because of the risk of complications, including torsion, rupture and the small potential of malignant transformation, estimated at between 1 and 3\% [2].

\section{Case report}

A 37-year-old female presented to the Accident and Emergency department with a two-week history of increas-

\footnotetext{
A. Malhotra $\cdot$ C. Grimes $\cdot$ M. Nikolić $(\bigotimes)$

Department of Surgery, Hinchingbrooke Hospital NHS Trust, Huntingdon, Cambridgeshire PE29 6NT, United Kingdom

e-mail:mzn@cantab.net
}

ing abdominal pain, distension, diarrhoea and fever. There were no respiratory, cardiovascular or urinary symptoms.

Three weeks earlier, the patient underwent a laparoscopic salpingo-oophorectomy for a left ovarian dermoid cyst. There was spillage of the cyst and an endobag was not used. Peritoneal washout was performed laparoscopically.

On examination, the patient was alert and orientated. The vital signs were as follows: heart rate 140 beats per minute; blood pressure $152 / 79 \mathrm{mmHg}$; tympanic temperature $38.1^{\circ} \mathrm{C}$ and respiratory rate 24 breaths per minute. The apex beat was not displaced and no heart murmurs were noted. The chest was clear on auscultation, whereas the abdomen revealed generalized tenderness with rigidity and rebound. There was no evidence of infection at the port sites. Bowel sounds were diminished. A clinical diagnosis of peritonitis was made.

Chest X-ray showed no abnormality, whereas abdominal $\mathrm{X}$-ray showed some generalised increased opacification consistent with the presence of free fluid. Computed tomography (CT) of the abdomen revealed a large amount of free fluid, with some thickening of the peritoneal surfaces, consistent with generalised peritonitis.

The blood results were as follows: haemoglobin $10.5 \mathrm{~g} / \mathrm{dL}$, white cell count $17.8 \times 10^{9} / \mathrm{L}$, neutrophils $15.5 \times 10^{9} / \mathrm{L}$, platelets $1,044 \times 10^{9} / \mathrm{L}$. The renal and liver function tests, calcium, phosphate and blood cultures were all normal. The C-reactive protein was raised at $245 \mathrm{mg} / \mathrm{l}($ normal $<6)$.

A diagnostic laparoscopy was performed and was converted to a laparotomy for peritoneal washout. Eleven days later, the patient developed multiple fluid anterior abdominal wall collections revealed by $\mathrm{CT}$ of her abdomen. Ultrasound-guided aspiration of one of these peritoneal collections showed no growth of organisms. A repeat abdominal CT showed an enlarging anterior wall collection of fluid and air (Fig. 1), as well as a hernia containing bowel inferior to the umbilicus. Exploration of the wound 


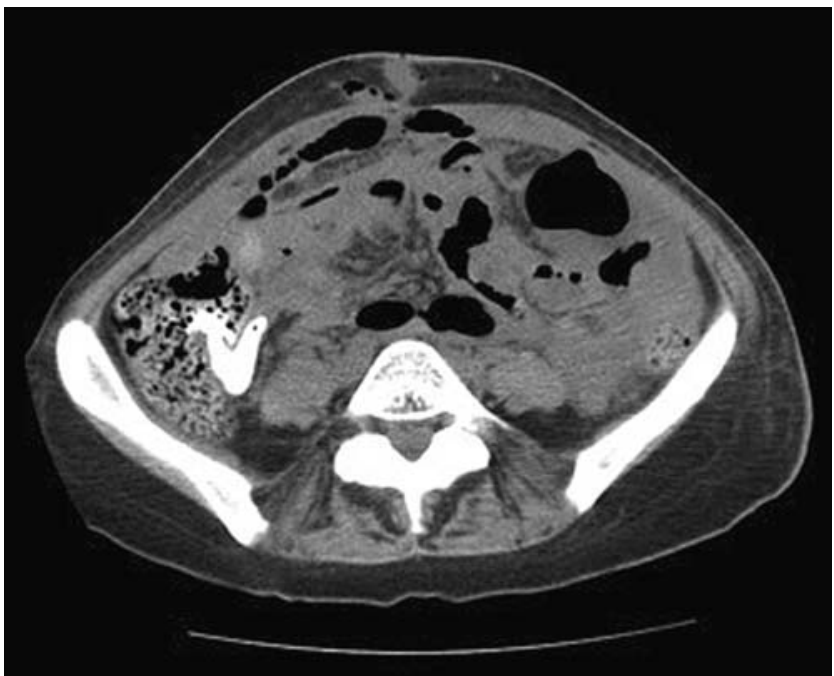

Fig. 1 Computed tomography (CT) axial section through the abdomen showing a collection of fluid and air, mainly the latter, immediately posterior to the anterior abdominal wall in the subcutaneous fat tissue

revealed yellow pus and necrotic material extending between the layers of the abdominal wall, but there was no extension of tracts into the peritoneal cavity. Ten days later, the lower third of the laparotomy wound broke down and initially there was discharge of frank pus from the wound; later an amylase-rich brown fluid and air were discharged. This was the formation of an enterocutaneous fistula.

\section{Discussion}

The laparoscopic removal of dermoid cysts has been shown to be safe, with most patients discharged the same day [3, 4]. The most significant potential complication of dermoid cyst removal is chemical peritonitis resulting from spillage. Although the rate of spillage during laparoscopic removal is approximately $27 \%$ [5], the incidence of clinical peritonitis following spillage during laparoscopy is estimated at only $0.2 \%[4]$.

The risk of spillage during removal of dermoid cysts is independent of age, operative technique or cyst size [6]. Concomitant oophorectomy, however, does reduce the chance of spillage, as does surgeon experience when laparoscopy, but not laparotomy, is performed.

The chances of spillage during laparoscopic removal have been shown to be reduced by the use of an endobag and complications are prevented by jet wash irrigation with large amounts of fluid [4, 7-10]. Failure to adequately irrigate the pelvis following spillage has been shown to lead to severe granulomatous peritonitis post-operatively [11]. This mani- fests at subsequent laparotomy as diffuse purulent peritonitis with scattered yellow sebaceous fragments [11, 12].

Fistula formation to bowel and bladder has been reported in cysts which have not been removed [13, 14]. Fistula formation results either from malignancy within the cyst or from a small amount of spillage of cyst contents, leading to peritonitis [15].

\section{Conclusion}

This case and literature review underline the importance of thorough washout of the pelvis following spillage from dermoid cysts removed laparoscopically. In addition, it is strongly recommended that endobags be used to minimise complications such as peritonitis and fistula formation.

Acknowledgement The authors acknowledge the contributions of the Department of Radiology at Hinchingbrooke Hospital, Huntingdon, UK.

\section{References}

1. Peterson WF, Prevost EC, Edmunds FT, Hundley JM Jr, Morris FK (1955) Benign cystic teratoma of the ovary: a clinico-statistical study of 1007 cases with review of the literature. Am J Obstet Gynecol 70(2):368-382

2. Richardson G, Robertson DI, O'Connor ME, Nation JG, Stuart GCE (1990) Malignant transformation occurring in mature cystic teratomas of the ovary. Can J Surg 33:499-503

3. Albini SM, Benadiva CA, Haverly K, Luciano AA (1994) Management of benign ovarian cystic teratomas: laparoscopy compared with laparotomy. J Am Assoc Gynecol Laparosc 1(3): 219-222

4. Shawki O, Soliman I, Ebrashy A, El Sadek M, Bahnassy A (2004) Laparoscopic management of ovarian dermoid cysts. MEFSJ 9 (1):58-65

5. Yuen PM, Yu KM, Yip SK, Lau WC, Rogers MS, Chang A (1997) A randomized prospective study of laparoscopy and laparotomy in the management of benign ovarian masses. Am J Obstet Gynecol 177:109-114

6. Milad MP, Olson E (1999) Factors that increase the risk of leakage during surgical removal of benign cystic teratomas. Hum Reprod 14(9):2264-2267

7. Bollen N, Camus M, Tournaye H, De Munck L, Devroey P (1992) Laparoscopic removal of benign mature teratoma. Hum Reprod 7:1429-1432

8. Chapron C, Bubuisson JB, Samouh N, Foulot H, Aubriot F-X, Amsquer Y, Morice P (1994) Treatment of ovarian dermoid cysts. Place and modalities of operative laparoscopy. Surg Endosc 8: 1092-1095

9. Nezhat C, Winer WK, Nezhat F (1989) Laparoscopic removal of dermoid cysts. Obstet Gynecol 73:278-280

10. Reich H, McGlynn F, Sekel L, Taylor P (1992) Laparoscopic management of ovarian dermoid cysts. J Reprod Med 37:640-644

11. Coccia ME, Becattini C, Bracco GL, Scarselli G (1996) Acute abdomen following dermoid cyst rupture during transvaginal 
ultrasonographically guided retrieval of oocytes. Hum Rep 11 (9):1897-1899

12. Waxman M, Boyce JG (1976) Intraperitoneal rupture of benign cystic ovarian teratoma. Obstet Gynecol 48(1Suppl):9S-13S

13. Stern JL, Buscema J, Rosenshein NB, Woodruff JD (1981) Spontaneous rupture of benign cystic teratomas. Obstet Gynecol 57:363-366
14. Shiels WE, Dueno F, Hernandez E (1986) Ovarian dermoid cyst complicated by an entero-ovarian fistula. Radiology 160:443-444 15. Okada S, Ohaki Y, Inoue K, Nakajo H, Kawamata H, Kumazaki $T$ (2005) A case of dermoid cyst of the ovary with malignant transformation complicated with small intestinal fistula formation. Radiat Med 23(6):443-446 